\title{
Determination by MODIS satellite-based methods of recent global trends in land surface aridity and degradation
}

\author{
Reiji KIMURA $^{\mathrm{a}, \dagger}$ and Masao MoriYama ${ }^{\mathrm{b}}$ \\ ${ }^{a}$ Arid Land Research Center, Tottori University, Tottori 680-0001, Japan \\ ${ }^{\mathrm{b}}$ Graduate School of Engineering, Nagasaki University, Nagasaki 852-8521, Japan
}

\begin{abstract}
The Aridity Index (AI; the ratio of precipitation to potential evaporation), is an indirect, essentially climatic index that has been used to identify global distributions of arid regions. Since the turn of the century, the increasingly widespread availability of satellite data has led many researchers to use it to assess desertification. In this study we used a satellite-based aridity index (SbAI) to investigate global changes of land surface aridity from 2000 to 2017. Degraded land areas were identified by using SbAI and the normalized difference vegetation index (NDVI). Here, degraded land include existing desert and the land having both permanent and temporal dust erodibility. Our results showed that actual land condition by SbAI became dryness than that derived from the climatic AI indicator in arid, semi-arid, and dry sub-humid regions and that the dryness was reflected in an increase in the extent of areas classified as hyper-arid. From 2000 to 2017, however, the annual extent of the wetter areas within arid regions (semi-arid and dry sub-humid regions) increased, and that of drier areas (hyper-arid and arid regions) decreased. The global area of degraded land decreased slightly between 2000 and 2017, and the annual average area for that period was $13.5 \times 10^{6} \mathrm{~km}^{2}(9.2 \%$ of total land area).
\end{abstract}

Key words: Aridity index, Degradation, Desertification, Drylands, Remote sensing

\section{Introduction}

Drylands are very sensitive to climate change and human activities (Rotenberg and Yakir, 2010; El-Beltagy and Madkour, 2012; Feng and Fu, 2013; IPCC, 2013; Huang et al. 2016), both of which are critical drivers of the changes that are degrading Earth's environment. Desertification is land degradation in arid, semi-arid and dry sub-humid regions resulting from various factors, including climatic variations and human activities (UNCCD, 2011), which affect both the livelihoods of people living in arid regions and the biophysical environments of those regions. Monitoring and early warning systems based on numerical modeling, remote sensing, and weather forecasting are needed to provide a better understanding of seasonal and annual variations of conditions in arid regions and thus to provide the means to prevent or mitigate desertification of those regions (e.g., Kar and Takeuchi, 2003; Dai, 2010; Kimura, 2016).

The United Nations Convention to Combat Desertification (UNCCD, 2011) advocates sustainable land management (SLM) by employing practices that minimize soil erosion, improve the capacity of the land to produce crops, and increase the income of people living in dryland areas. Thus, the goal of the UNCCD is to identify those practices that are sustainable in dryland areas (UN Earth Summit, 1992; Cowie et al., 2011). There is an urgent need to develop SLM in arid regions, which are vulnerable to the impacts of global warming (IPCC, 2013). Though SLM

Received; January 27, 2019

Accepted; March 28, 2019

'Corresponding Author: rkimura@tottori-u.ac.jp

DOI: 10.2480/agrmet.D-19-00003 has been applied to combat desertification in many parts of the world, it has been unsuccessful in many dryland areas. Effective application of SLM has been hindered by a lack of understanding of the worldwide distribution of dryland regions and the extent of their aridification (Gibbs and Salmon, 2015).

Of several climate-based methods used to define arid regions, the aridity index (AI) is most widely used (UNESCO, 1979; UNEP, 1992, 1997; Millennium Ecosystem Assessment, 2005; Cherlet et al., 2018). The AI expresses the degree of dryness of the climate at a given location as a generalized function of the ratio of annual precipitation (Pr) to annual potential evapotranspiration (Ep) and uses that ratio to classify arid regions as hyper-arid, arid, semi-arid, dry sub-humid, or humid (Cherlet et al., 2018; Millennium Ecosystem Assessment, 2005; UNEP, 1992, 1997). However, Gamo et al. (2013) suggested that the AI is essentially a climatic index and may not provide a system for meaningful classification of levels of aridity.

Kimura (2018) developed a method to monitor the global distribution of areas of degraded land based on a metric of dust erodibility calculated from the normalized difference vegetation index (NDVI) and a satellite-based aridity index (SbAI; defined by Kimura and Moriyama, 2014). Kimura and Moriyama (2019) extended the SbAI-based method to allow classification of levels of aridity. First, they examined annual variations of AIs from 2001 to 2013 globally using the precipitation and meteorological reanalysis datasets, and the global distribution and annual changes of the AI were analyzed. Second, they proposed a method to monitor the actual extent of aridity using the SbAI. As a result, the SbAI decreased with increases of the AI and was significantly correlated with the AI. On the basis of the relationship between the AI and SbAI, they classified arid 
regions with the SbAI and showed that these classifications characterized land conditions better than those based on the AI, so that $\mathrm{SbAI}$ provides a numerical satellite based indicator of the actual degree of dryness at a given location. Their results suggest that both aridification and wetting of land can be detected by comparing the $\mathrm{SbAI}$ (= actual conditions) with the $\mathrm{AI}$ (= climatic conditions). This method should be extended to the monitoring of recent global trends of land surface aridity, and describe their problems and advantage.

In this study we used the above SbAI-based method to examine global trends of land-surface aridity from 2000 to the present, covering the period of availability of Moderate Resolution Imaging Spectroradiometer (MODIS) satellite data. We then used the SbAI and NDVI indexes to identify the global distribution of degraded drylands.

\section{Methods}

\subsection{Satellite-based aridity index}

Daily values of SbAI, the physical meaning of which is the opposite of heat capacity determined by land surface wetness, have been expressed by Kimura and Moriyama (2014) as

$$
\mathrm{SbAI}=\frac{\Delta T_{\mathrm{s}}}{R_{\mathrm{s}}}
$$

where

$$
R_{\mathrm{s}}=(1-r) S_{0} \cos \theta_{\mathrm{c}} .
$$

$\Delta T_{\mathrm{s}}$ is the daily difference between daytime and nighttime land surface temperatures (LSTs), and $R_{\mathrm{S}}$ is absorbed solar radiation calculated from broadband albedo $r$, the solar constant $S_{0}$ $\left(1367 \mathrm{~W} \mathrm{~m}^{-2}\right)$, and the solar zenith at the Sun's apex, $\theta_{\mathrm{c}} . \Delta T_{\mathrm{s}}$ reflects surface dryness, but is also affected by other factors, especially solar radiation. To compensate for the effect of solar radiation, $\Delta T_{\mathrm{s}}$ is divided by $R_{\mathrm{s}}$ in Equation (1). For a dry surface, $\mathrm{SbAI}$ is large if $\Delta T_{\mathrm{s}}$ is large, and $\Delta T_{\mathrm{s}}$ is large when low soil water content lowers the heat capacity of soil.

Calculations of SbAI were based here on the method of Kimura and Moriyama (2014) and used MODIS products MOD09CMG and MOD11C1. These are daily global Climate Modeling Grids (CMGs) presented as geographic latitude/longitude projections with $0.05^{\circ}$ resolution (https://modis-land.gsfc.nasa.gov/MODLAND_grid.html).

Cloud cover was derived from cloud flag information in the satellite data. Daily SbAI values were calculated using only "good" data according to the quality flag. Final SbAI data were averaged by year.

Because our aim was to monitor arid regions, we calculated SbAIs only between latitudes $55^{\circ} \mathrm{N}$ and $55^{\circ} \mathrm{S}$, thus excluding tundra in areas of subarctic climate (Gamo et al., 2013). The horizontal resolution of the SbAI data was approximately $0.05^{\circ}$ (longitude and latitude) according to the 1984 World Geodetic System (WGS 84) coordinate standard (Kimura and Moriyama, 2014). Areas $\left(\mathrm{km}^{2}\right)$ were estimated by translating the original image to an equal-area map projection (Eckert 4 projection [EPSG: 54012]; one pixel was $5.6 \mathrm{~km} \times 5.6 \mathrm{~km}$ ). The total land area, including Antarctica, was $1.47 \times 10^{8} \mathrm{~km}^{2}$. The analysis period was 2000-2017, corresponding to the period of availability of MODIS data.

\subsection{Delineation of degraded land area based on dust erodibility}

Kimura (2017) used MODIS data to develop a method for monitoring degraded land in east Asia on the basis of dust erodibility in areas with vegetation (NDVI) and aridity (SbAI) indices that indicate high susceptibility to dust formation. The areas identified in East Asia by Kimura (2017) corresponded well with the sources of dust events over Japan as identified on a dust erodibility map of China and Mongolia. Kimura (2018) expanded the method and applied it to monitor global-scale changes in the areas of degraded land from 2012 to 2016.

Empirical evidence indicates that under conditions where $\mathrm{NDVI}<0.2$ and $\mathrm{SbAI}>0.03$, dust outbreaks are likely to occur. These threshold values were determined on the basis of the spatiotemporal correspondence of observational NDVI and SbAI data indicative of dust generation in China and Mongolia with Asian dust events in Japan from 2000 to 2011 (Kimura, 2012a, 2012b; Kimura and Moriyama, 2014). Kimura (2017) previously defined areas that meet both of these criteria as 'degraded land'. Although this terminology suggests a permanent condition (Mannava and Ndegwa, 2007; Marini and Talbi, 2009), degraded land (or parts thereof) can recover on a seasonal or annual basis (Kimura, 2017). Therefore, degraded land areas defined here include existing desert and both permanently and temporarily degraded land.

Daily NDVI is calculated from two channels of MODIS data, the near-infrared (NIR) and visible (RED) wavelengths, as

$$
\mathrm{NDVI}=\frac{\rho_{\mathrm{NIR}}-\rho_{\mathrm{RED}}}{\rho_{\mathrm{NIR}}+\rho_{\mathrm{RED}}}
$$

where $\rho_{\mathrm{NIR}}$ is surface reflectance from MODIS band 2 (841 to $876 \mathrm{~nm})$ and $\rho_{\mathrm{RED}}$ is from MODIS band 1 (620 to $\left.670 \mathrm{~nm}\right)$. NDVI is calculated by using MODIS data products MOD09CMG with $0.05^{\circ}$ resolution (the same resolution as SbAI data). In this study, the threshold value used for SbAI was 0.025 , rather than 0.03 (Kimura and Moriyama, 2019), because here annual average values of SbAI were used, whereas the threshold value of 0.03 was obtained from monthly maxima (Kimura, 2018). The threshold value of NDVI used here (0.2) was determined as an annual maximum value. The reason why annual average values of SbAI were used was that based AI was also annual base (= annual Pr to annual Ep) when the relationship between AI and SbAI was examined (Kimura, 2018). In the case of arid regions, vegetation amounts were very low and its characteristic was cancelled when the annual average was used. We assumed that the maximum value of NDVI indicated the potential vegetation amounts under the limited rainfall. The global distribution of annual maximum NDVI $<0.2$ and annual averaged $\mathrm{SbAI}>0.025$ were examined and defined areas that meet both of these criteria as degraded land.

\section{Results and discussion}

\subsection{Recent trends of land surface aridity determined from SbAI}

Comparison of the global distribution of average annual SbAI for 2000 to 2017 (this study; Fig. 1a) with the corresponding 
global aridity classification according to AI (data not shown) by Cherlet et al. (2018) and Millennium Ecosystem Assessment (2005) shows that SbAI reproduces well their humid tropical zones and arid lands. However, the AI defined by UNEP (1992) is a water-balance based climatic index for aridity that cannot express actual conditions of aridity (Gamo et al., 2013). That is, they have indicated that objective criteria with physical and biological meaning are needed to prepare a map of the global distribution of arid regions. An important point made by Gamo et al. (2013) is that the AI is just a climatic factor - it is not an actual indication of arid conditions - whereas the NDVI is an indication of an actual condition (abundance of vegetation) related to the climatic condition. Relevant physical and biological criteria include the AI and NDVI. They proposed a delimited methodology that combines the aridity and vegetation indices. On the other hand, the physical interpretation of the $\mathrm{SbAI}$ as a metric of the reciprocal of heat capacity is based on estimating heat capacity from the ratio of the amplitude of the LST and incident net solar radiation. Therefore, SbAI has been used to successfully detect the actual land surface aridity related to dust occurrence (Kimura, 2016, 2017; Kimura and Moriyama, 2019). SbAI may be likely related to the actual land surface aridity more directly than NDVI at a physical viewpoint.

Kimura and Moriyama (2019) showed that SbAI decreased with increasing AI and was significantly correlated with AI.
Based on the curve approximated from this correlation, the following simple categorization of arid regions based on SbAI values (Fig. 1a) is possible (Fig. 1b):

Hyper-arid: $\mathrm{SbAI}>0.025$

Arid: $0.022 \leq \mathrm{SbAI} \leq 0.025$

Semi-arid: $0.017 \leq \mathrm{SbAI}<0.022$

Dry sub-humid: $0.015 \leq \mathrm{SbAI}<0.017$.

Using these classification criteria, the total global area of dryland and percentage of total land area that we determined from $\mathrm{SbAI}$ data $\left(60.4 \times 10^{6} \mathrm{~km}^{2}\right.$ and $41.0 \%$, respectively; Table 1) are almost identical to the values $\left(60.9 \times 10^{6} \mathrm{~km}^{2}\right.$, $41.1 \%$ ) reported on the basis of AI by Millennium Ecosystem Assessment (2005). Although the global distributions of our four SbAI-based classifications (Fig. 1b) are similar to those reported on the basis of AI and NDVI by Gamo et al. (2013), the areas for individual classes and their percentages of total land area differ (Table 1). Our SbAI-based areas and percentages are higher than those of Millennium Ecosystem Assessment (2005) for the hyper-arid class $(+6.8 \%)$, and lower for the arid $(-3.8 \%)$, semi-arid $(-0.9 \%)$, and dry sub-humid $(-2.2 \%)$ classes. The differences between actual (SbAI-based) and climatic (AI-based) aridity were especially large for the hyper-arid and arid regions (Table 1).

In the relatively brief period from 2000 to 2017 , our
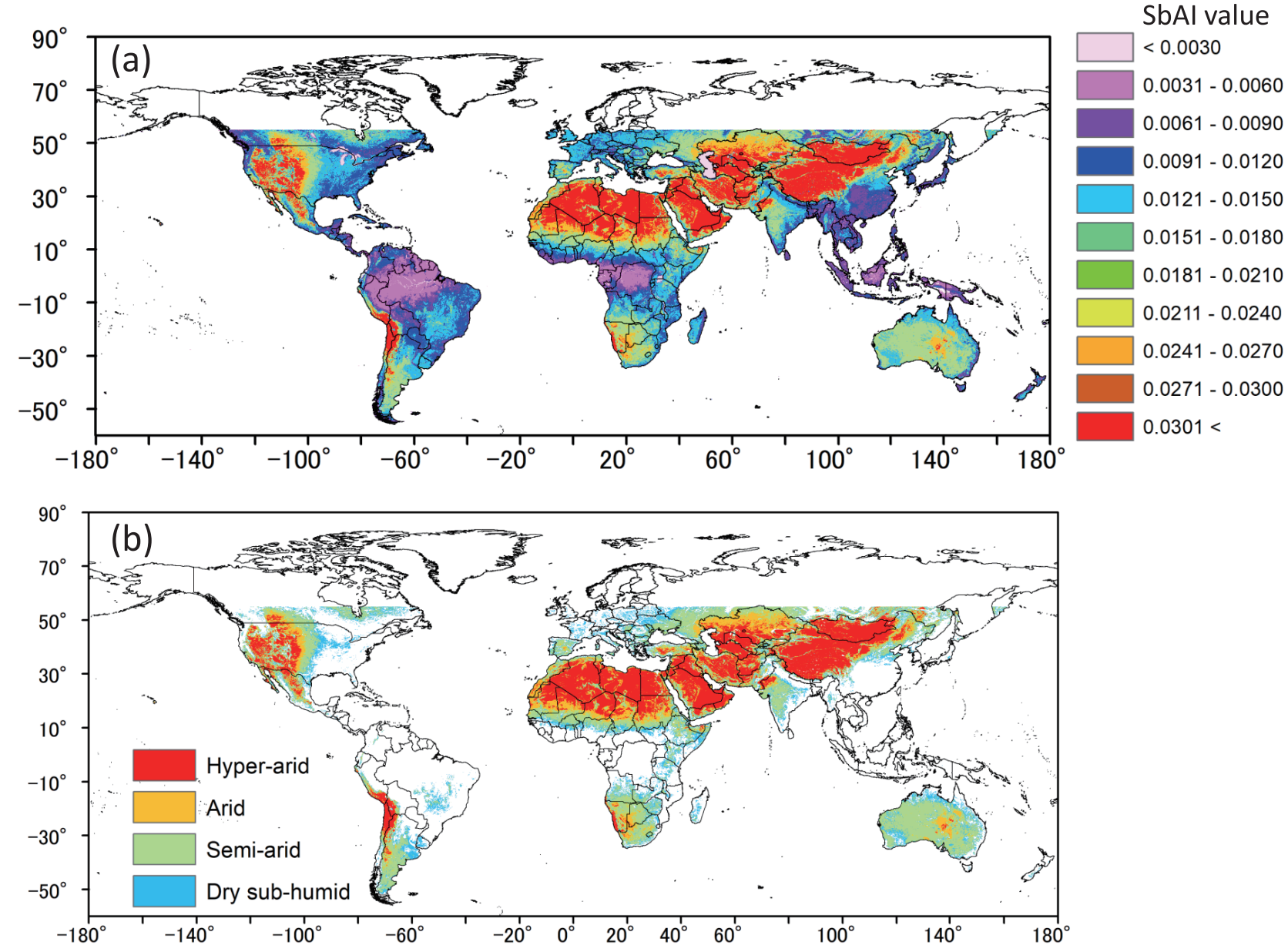

Fig. 1. Global distributions of (a) (2000-2017) average annual SbAI and (b) aridity classifications determined from SbAI. 
SbAI-based data show that there were annual changes in the areas of each class of dryland and their percentages of total land area (Fig. 2). There was a strong decreasing trend for hyper-arid regions $\left(R^{2}=0.29: p<0.05\right)$, a weaker decreasing trend for arid regions $\left(R^{2}=0.04\right)$, but weak increasing trends for semi-arid $\left(R^{2}=0.01\right)$ and dry sub-humid $\left(R^{2}=0.01\right)$ regions. Actual land conditions by SbAI indicated dryness than those by AI-based climatic index (Table 1). Nonetheless, our SbAI data for 2000-2017 indicate that areas of relatively wet dryland (semi-arid and dry sub-humid areas) have been increasing year by year, whereas the drier areas (hyper-arid and arid regions) have been decreasing (Fig. 2).

The global distribution of correlation coefficients for increasing (drying) trends or decreasing (wetting) trends of daily SbAI values from 2000 to 2017 is shown in Fig. 3. Black areas on land indicate few changes of SbAI where the calculation of correlation coefficients was impossible (e.g., desert areas).
Green areas also indicate few variations of SbAI. Drying trends (blue; $p<0.001$ ) were few, but can be seen in parts of Brazil, western Africa, China, and south-east Asia, whereas wetting trends (orange; $p<0.001$ ) can be seen in the hyper-arid and arid regions shown in Fig. 1b. This distribution of correlation coefficients corresponds to the data shown in Fig. 2; that is, the area occupied by relatively dry regions (hyper-arid and arid regions) decreased year by year. The reasons for these wetting trends shown in Fig. 3 are unclear, except for those in northwest China and western India, as explained below.

In China in 1999, the Chinese government initiated the 'Grain for Green Program' to promote greening by gradually replacing farming areas with natural vegetation (Kimura et al., 2006). For example, this program resulted in forested area increasing dramatically in extent between 2002 and 2004 (http://www.spc.jst.go.jp/statistics/statictisc_index.html). Although it is unclear whether this increase was entirely a result of the

Table 1. Global average land areas and percentages of total land area determined from SbAI for four dryland classes for 2000 to 2017 (this study) compared to estimates from the Millennium Ecosystem Assessment (2005).

\begin{tabular}{|c|c|c|c|c|c|}
\hline \multicolumn{3}{|l|}{ This study } & \multicolumn{3}{|c|}{ Millennium Ecosystem Assessment (2005) } \\
\hline Class & Area $\left(\times 10^{6} \mathrm{~km}^{2}\right)$ & Area $(\%)$ & Class & Area $\left(\times 10^{6} \mathrm{~km}^{2}\right)$ & Area $(\%)$ \\
\hline$\frac{\text { Hyper-arid }}{(\mathrm{SbAI}>0.025)}$ & 19.8 & 13.4 & $\frac{\text { Hyper-arid }}{(<0.05)}$ & 9.8 & 6.6 \\
\hline 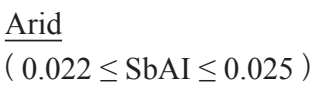 & 10.0 & 6.8 & $\frac{\text { Arid }}{(0.05-0.20)}$ & 15.7 & 10.6 \\
\hline$\frac{\text { Semi-arid }}{(0.017 \leq \mathrm{SbAI}<0.022)}$ & 21.1 & 14.3 & $\frac{\text { Semi-arid }}{(0.20-0.50)}$ & 22.6 & 15.2 \\
\hline$\frac{\text { Dry sub-humid }}{(0.015 \leq \mathrm{SbAI}<0.017)}$ & 9.5 & 6.5 & $\frac{\text { Dry sub-humid }}{(0.50-0.65)}$ & 12.8 & 8.7 \\
\hline Sum & 60.4 & 41.0 & Sum & 60.9 & 41.1 \\
\hline
\end{tabular}

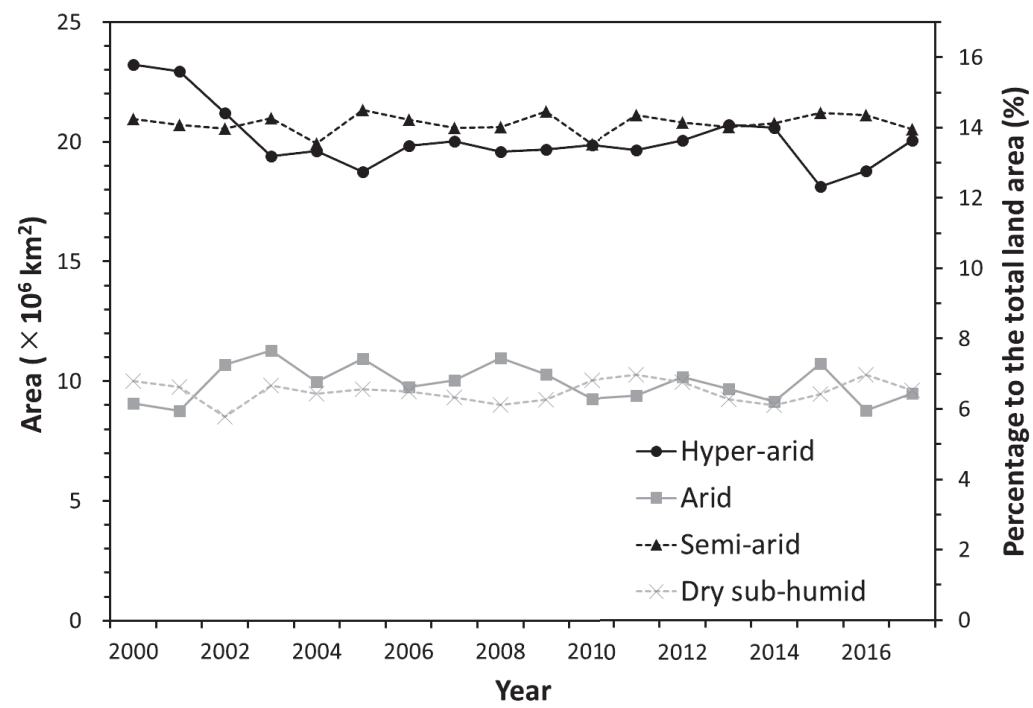

Fig. 2. Annual changes (2000-2017) of individual areas of the four classes of dryland and their percentages of total land area. 


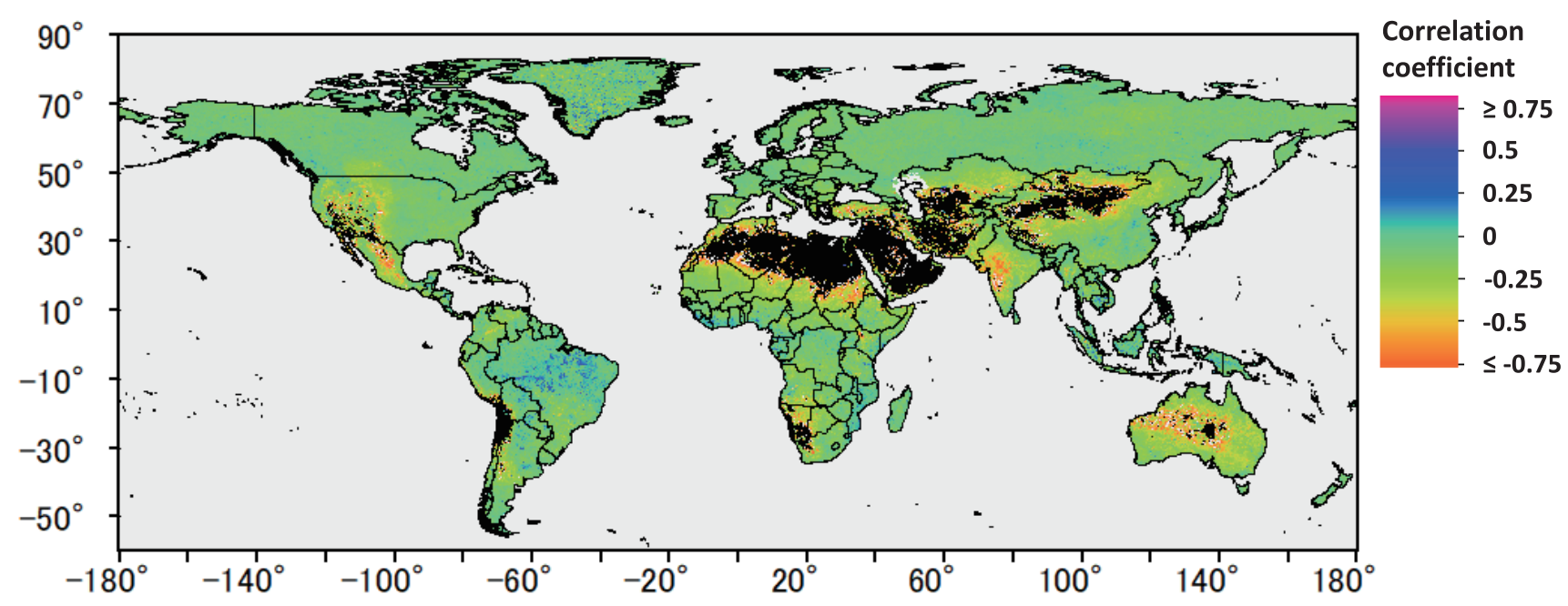

Fig. 3. Global distribution of correlation coefficients for the increasing (drying) or decreasing (wetting) trends of daily SbAI (2000-2017).
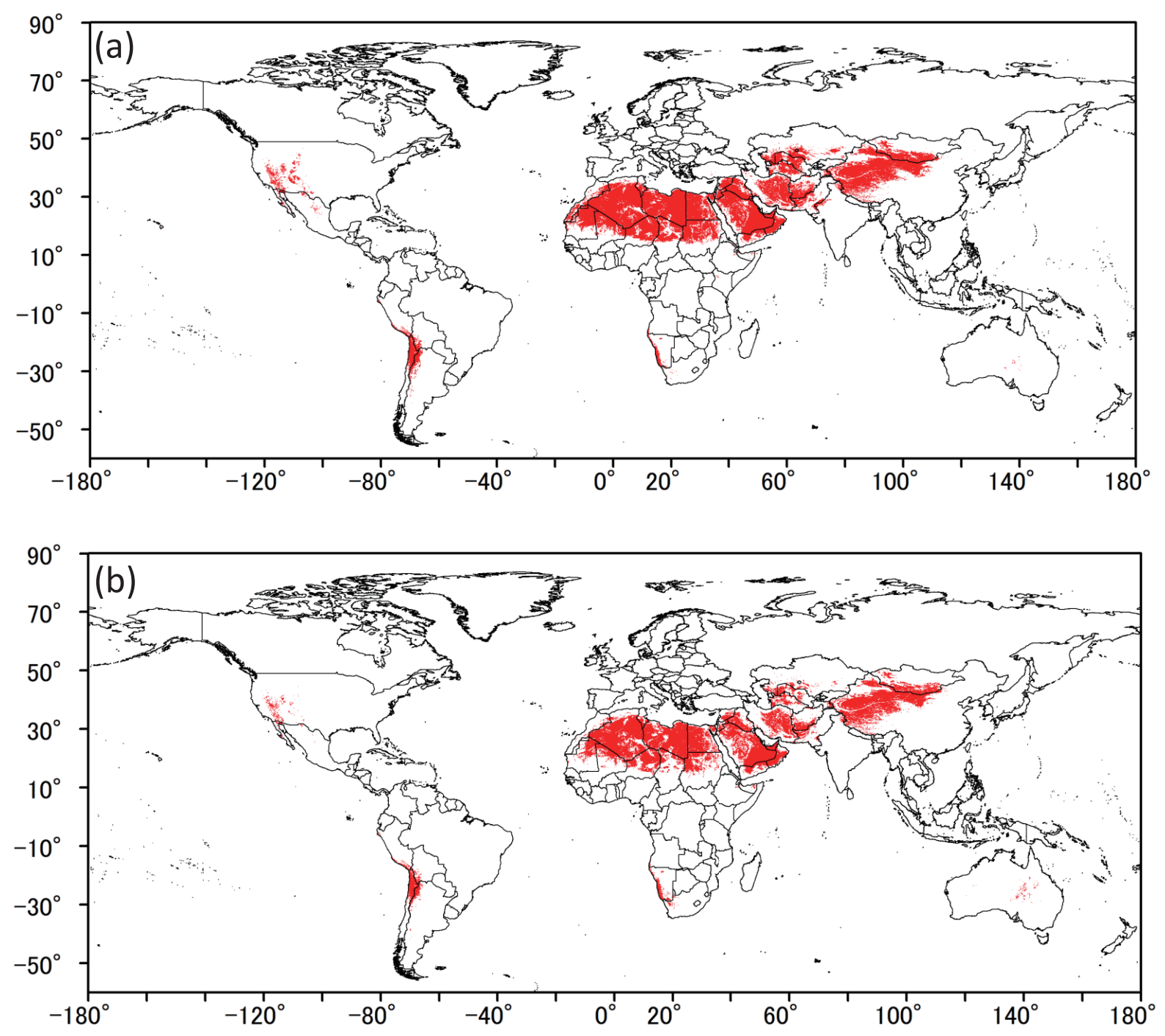

Fig. 4. Global distributions of degraded land determined in this study for (a) 2000 and (b) 2015. 


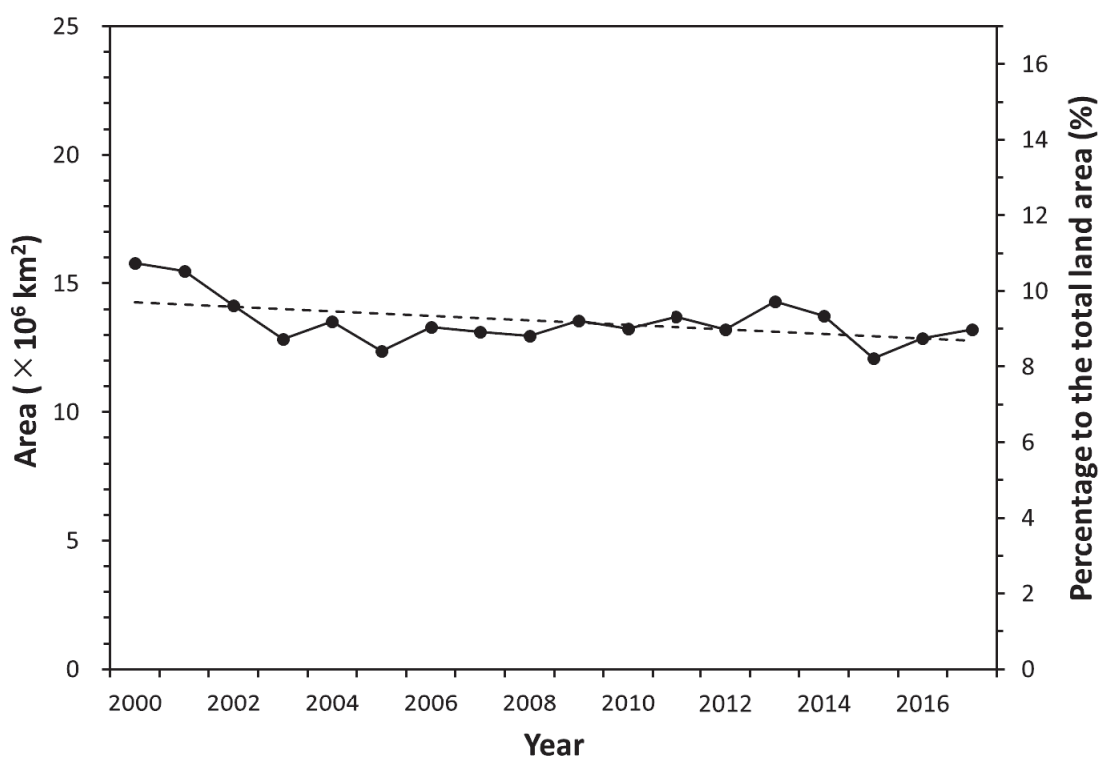

Fig. 5. Annual changes (2000-2017) of areas of degraded land and the percentages of total land area classified as degraded.

Grain for Green Program, the program certainly contributed to it (Kimura, 2012a; 2012b). According to a forest survey of India, forest cover in western states (Gujarat, Karnataka, Madhya Pradesh, Maharashtra, and Rajasthan) increased from 1999 to 2009 in response to reforestation activities, community forest management, and the implementation of appropriate government forestry policies (Bhushan, 2017).

Chen et al. (2019) also obtained similar result, even if the vegetation indices like NDVI was different from SbAI at a physical viewpoint. That is, recent satellite product (MODIS LAI from 2000 to 2017) revealed a greening pattern that was strikingly prominent in China and India implementing human land use management. Other wetting or drying trends in Fig. 3 were also recognized in the global map of annual average MODIS LAI for 2000-2017 (Chen et al., 2019).

\subsection{Global distributions of areas of degraded land on the basis of dust erodibility}

The global distributions of degraded land that we determined for 2000-2017 on the basis of dust erodibility showed maximum and minimum areas in 2000 and 2015, respectively (Fig. 4). The largest deserts - the Great Basin in North America, the Atacama and Patagonian deserts in South America, the Sahara and Kalahari in Africa, and the Syrian, Arabian, Gobi, and Taklamakan deserts in Asia - are well reproduced by our degraded land classification.

Annual changes of the global area of degraded land from 2000 to 2017 (Fig. 5) show a small decrease during 2000 to $2017\left(R^{2}=0.24: p<0.05\right)$. Chen et al. (2019) indicated similar result, that is, recent MODIS satellite data from 2000 to 2017 showed increasing leaf area of vegetation globally due to direct factors (human land-use management) and indirect factors such as climate change. This translated to a net increase in leaf area of $2.3 \%$ per decade to the global vegetated area.
As a proportion of the total land area, the area of degraded land decreased by about $1 \%$, that is, by about $1.5 \times 10^{6} \mathrm{~km}^{2}$ during the 18 years we considered. The average area of degraded land for those 18 years was $13.5 \times 10^{6} \mathrm{~km}^{2}(9.2 \%)$. Although this average area is larger than those previously determined by UNEP (1992) $\left(10 \times 10^{6} \mathrm{~km}^{2}(7 \%)\right)$ and Millennium Ecosystem Assessment (2005) $\left(12.2 \times 10^{6} \mathrm{~km}^{2}(8.3 \%)\right)$, our results are in basic agreement if the differences of analysis periods are taken into account.

\section{Conclusions}

Of several climate-based methods that have been used to define dryland regions, the aridity index (AI) is most widely used. The AI method is used to classify drylands as hyper-arid, arid, semi-arid, or dry sub-humid. However, researchers have pointed out that the $\mathrm{AI}$ is in fact a climatic factor, not a direct indicator of arid conditions. The several advantages of using the SbAI-based method are as follows.

- Since 2000, MODIS has provided daytime and nighttime satellite data recorded over equivalent locations.

- Because there are lengthy cloudless periods in dryland areas, there are more usable daytime and nighttime MODIS satellite data available for global analyses (in arid regions: average $\sim 8000$ data points, maximum $\sim 11400$ ).

- The resolution of SbAI data is higher than that of AI data, which is based on meteorological data.

- SbAI is a numerical satellite based indicator of the actual degree of dryness at a given location.

Because usable SbAI data in equatorial regions are fewer than in arid regions (the smallest dataset was 210 data points for Sumatra, Indonesia), application of SbAI will be most effective for monitoring desertification in arid regions.

Continuous monitoring of arid regions will be important in the near future because of their sensitivity to climate change and 
human activities. For such monitoring, a system is needed to manage data from MODIS and its successors, such as the Second Generation Global Imager (SGLI) sensor on the Global Change Observation Mission - Climate (GCOM-C) satellite launched on 24 December 2017. Such systems will facilitate sustainable land management in arid regions of the world.

\section{Acknowledgments}

I appreciate invaluable comments by two reviewers and editor on this paper. This study was supported by JSPS KAKENHI Grant Number 17H04634, 17H01626, and 18K05877.

\section{References}

Bhushan S, 2017: Trend of deforestation in India: A comparative approach to identify the qualitative and quantitative change of natural vegetation cover. International Journal of Scientific Research and Management 5, 6538-6547.

Chen C, Park T, Wang X, Piao S, Xu B, Chaturvedi RK, Fuchs R, Brovkin V, Ciais P, Fensholt R, Tømmervik H, Bala G, Zhu Z, Nemani RR, Myneni RB, 2019: China and India lead in greening of the world through land-use management. Nature Sustainability 2, 122-129.

Cherlet M, Hutchinson C, Reynolds J, Hill J, Sommer S, von Maltitz G, 2018: World Atlas of Desertification. Publication Office of the European Union, Luxembourg, pp. 248.

Cowie AL, Penman TD, Gorissen L, Winslow MD, Lehmann J, Tyrrell TD, Twomlow S, Wilkes A, Lal R, Jones JW, Paulsch A, Kellner K, Akhtar-Schuster M, 2011: Towards sustainable land management in the drylands: Scientific connections in monitoring and assessing dryland degradation, climate change and biodiversity. Land Degradation \& Development 22, 248-260.

Dai A, 2010: Drought under global warming: a review. Wiley Interdisciplinary Reviews, Climate Change 2, 45-65.

El-Beltagy A, Madkour M, 2012: Impact of climate change on arid lands agriculture. Agriculture \& Food Security 1. 1-12.

Feng S, Fu Q, 2013: Expansion of global drylands under a warming climate. Atmospheric Chemistry and Physics 13, 10081-10094.

Gamo M, Shinoda M, Maeda T, 2013: Classification of arid lands, including soil degradation and irrigated areas, based on vegetation and aridity indices. International Journal of Remote Sensing 34, 6701-6722.

Gibbs HK, Salmon JM, 2015: Mapping the world's degraded lands. Applied Geography 57, 12-21.

Huang J, Ji M, Xie Y, Wang S, He Y, Ran J, 2016: Global semi-arid climate change over last 60 years. Climate Dynamics 46, 1131-1150.

IPCC, 2013: Climate Change 2013: The Physical Science Basis. Contribution of Working Group I to the Fifth Assessment Report of the Intergovernmental Panel on Climate Change. Cambridge University Press, Cambridge, pp. 1535.

Kar A, Takeuchi K, 2003: Towards an early warning system for desertification (Early warning systems, Edition: $1^{\text {st }}$, Chapter), UNCCD Secretariat, Bonn, pp. 32.

Kimura R, 2012a: Factors contributing to dust storms in source regions producing the yellow-sand phenomena observed in Japan from 1993 to 2002. Journal of Arid Environments 80, 40-44.

Kimura R, 2012b: Effect of strong wind and land cover in dust source regions on the Asian dust events over Japan from 2000 to 2011. SOLA 8, 77-80.

Kimura R, 2016: Satellite-based mapping of dust erodibility in northeast Asia. Natural Hazards, DOI: 10.1007/s11069-016-2393-y

Kimura R, 2017: Validation and application of the monitoring method for degraded land area based on a dust erodibility in eastern Asia. International Journal of Remote Sensing 38, 4553-4564.

Kimura R, 2018: Global distribution of degraded land area based on dust erodibility determined from satellite data. International Journal of Remote Sensing, DOI: $10.1080 / 01431161.2018 .1444295$

Kimura R, Fan J, Zhang X, Takayama N, Kamichika M, Matsuoka N, 2006: Evapotranspiration over the grassland field in the Liudaogou basin of the Loess Plateau, China. Acta Oecologica 29, 45-53.

Kimura R, Moriyama M, 2014: Application of a satellite-based aridity index in dust source regions of northeast Asia. Journal of Arid Environments 109, 31-38.

Kimura R, Moriyama M, 2019: Recent trends of annual aridity indices and classification of arid regions with satellite-based aridity indices. Remote Sensing in Earth Systems Sciences. DOI: 10.1007/s41976-019-00014-w (Online First)

Mannava VKS, Ndegwa N, 2007: Climate and land degradation. Springer, Berlin, pp. 38.

Marini A, Talbi M, 2009: Desertification and risk analysis using high and medium resolution satellite data. Springer Science + Business Media, 157-170.

Millennium Ecosystem Assessment, 2005: Ecosystems and Human Well-being. World Resources Institute, Washington, pp. 25.

Rotenberg E, Yakir D, 2010: Contribution of semi-arid forests to the climate system. Science 327, 451-454.

UNCCD, 2011: Desertification: a visual synthesis. UNCCD Secretariat, Bonn, pp. 50.

UN Earth Summit, 1992: Definition of sustainable land management (SLM). www.fao.org/sustainability/frameworks-approaches/en/ (Accessed 10 Apr 2018).

UNEP, 1992: World Atlas of Desertification. Arnold, London, pp. 69.

UNEP, 1997: World Atlas of Desertification. Arnold, London, pp. 182.

UNESCO, 1979: Map of the world distribution of arid regions: Map at scale 1:25,000,000 with explanatory note. MAB Technical Notes 7, Paris, pp. 54. 